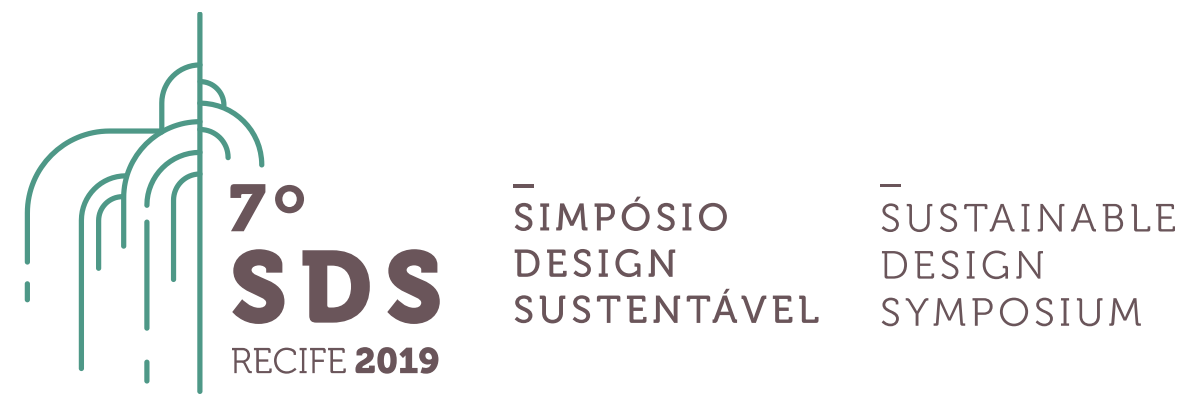

\title{
Ressignificação do papel Kraft descartado: possibilidade de novos produtos através da reciclagem
}

\author{
Thais Soares de Brito $^{1}$, Nubia Suely Silva Santos ${ }^{2}$ \\ ${ }^{1}$ Universidade do Estado do Pará, Graduanda em bacharelado em design, thaisbritodesigner@gmail.com \\ ${ }^{2}$ Universidade do Estado do Pará, Doutora em Engenharia Mecânica, nubiatrib@yahoo.com.br
}

\begin{abstract}
Resumo. A sustentabilidade tornou-se recorrente em um meio onde o consumo imprudente e o uso abusivo do capital natural diminuem a qualidade de vida das gerações atuais e futuras. Assim, este artigo discute a reciclagem de papel Kraft e aplicação em produtos como solução para a ampliação de seu ciclo de vida, a fim de evitar a eliminação direta na natureza, evitando que outro produto ou material vá para o aterro sanitário e para a natureza degradar em seu tempo normal.
\end{abstract}

Palavras-chave. Sustentabilidade; Ciclo de vida do produto; Papel reciclado; Papel Kraft.

\section{Introdução}

A sobreutiliação dos recursos ambientais e sua degradabilidade provém, como um dos fatores originários, do mundo pós segunda guerra mundial, onde havia a extensão da urbanização desordenada e industrialização acelerada. Mas foi na mesma época que tornou-se forte movimentos que defendem o meio ambiente. O movimento ambientalista vigorou-se como ativista e político em que as problemáticas ambientais deveriam ser evitadas por mudanças nos valores e instituições sociais (AFONSO, 2006, p.19).

O desenvolvimento sustentável veio para garantir "a qualidade de vida das gerações atuais e futuras, sem destruir sua base de sustentação, referindo-se ao meio ambiente." (VIEGAS, SALLES, 2012, p.3,). Porém, a extração insensata dos recursos renováveis e não renováveis como uso de matéria-prima é para uma população a qual cresce mais a cada respiro e para uma indústria que visa lucro. Todavia, a então sustentabilidade permite cuidados ao capital natural através de uma ação que não o prejudique ao mesmo tempo que leva em consideração a capacidade de recuperação natural. De acordo com Manzini (2008, p.23), estar de acordo com sustentabilidade, "um sistema de produção, uso e consumo tem que ir de encontro das demandas da sociedade por produtos e serviços sem perturbar os ciclos naturais e sem empobrecer o capital natural.".

Sendo assim, a reciclagem de diversos materiais pode ser uma via sustentável por permitir 
o respeito ao meio ambiente e contribuição para o equilíbrio dos ciclos naturais, pois ao invés de "decretar o fim de vida do produto" o mesmo volta ao ciclo de forma a ser utilizado novamente. De acordo com Kazazian (2009, p.50), "os tempos da natureza se organizam na forma de ciclos de diversas durações que regulam sua existência.". Um produto também possui um ciclo de vida e a sua análise "tem sido largamente usada pelos designers interessados em avaliar o impacto ambiental dos produtos." Conforme Manzini (2016, p.91) o ciclo de vida considera o "produto desde a extração dos recursos necessários para a produção de materiais que compõe [nascimento] até o último tratamento [morte] desses mesmos materiais após o uso do produto".

O papel descartado, antes utilizado em impressos, embalagens e em outras aplicações, pode ser ressignificado fazendo novos produtos através da sua reciclagem, além de permitir a renovação do seu ciclo de vida e a possibilidade de evitar seu descarte imediato de forma inadequada. Dessa forma o presente trabalho busca tratar da reciclagem do papel e sua aplicação em produtos, mais especificamente o papel kraft como uma solução a redução de mais um material descartado no meio ambiente e a qualidade de vida as gerações futuras.

\section{Papel reciclado}

O termo papel é originário do latim "papyrus", remetendo a papiro, a qual é uma planta, proveniente do Egito, onde retirava-se as fibras para a fabricação não só de folhas feitas para a escrita, mas também para a fabricação de cordas. Diz-se que o papiro foi o primeiro material feito para escrever, porém antes as escritas eram realizadas em outros materiais, dos quais cita-se as tabuletas de pedras e argilas (MORAIS et al 2015, p.3). Atualmente o papel é um dos principais meios para escrever, informar, etc.

Sendo assim, para realizar a fabricação de uma tonelada de papel novo é necessário 50 a 60 eucaliptos, $100 \mathrm{mil}$ litros de água e $5 \mathrm{mil} \mathrm{KW/h}$ de energia, mas para reciclar "é preciso $1200 \mathrm{~kg}$ de papel velho, 2 mil litros de água e de 1000 a $2500 \mathrm{KW} / \mathrm{h}$ " segundo Rosa (et al 2005,p.6). Souza, Silva e Junior (2012, p.3) afirmam que "a reciclagem incide no emprego do papel velho para aquisição do papel novo." Este "método limitado até o final da década de sessenta" foi forma que surgiu como solução a crescente poluição ambiental, onde reaproveitar os detritos sólidos amenizava tal problemática.

Também é importante frisar que o papel possui vantagem de ser reciclado, de modo artesanal ou industrial, mais de uma vez dependendo do tamanho da fibra. Ainda de acordo com o autor supracitado, "para aproximadamente 50 quilos de papel reciclado, poupa-se o corte de uma árvore." E as vantagens geradas através da reciclagem é a proteção do capital natural, extensão a vida útil das reservas naturais e redução ao impacto ambiental, além da diminuição "da necessidade de áreas para aterro devido à redução do volume de resíduos a serem depositados".

\subsection{Reciclagem de papel kraft}

De acordo com Klock, Andrade e Hernandez (2013, p.66), o chamado processo soda foi o pioneiro método químico de polpação "reconhecido com a utilização de uma solução alcalina forte de hidróxido de sódio para deslignificação de cavacos de madeira". Tal processo foi patenteado no ano de 1854 e com a inclusão da "incineração do licor de soda gasto para recuperação do álcali utilizado no processo", foi realizado outro processo de patente no ano de 1865 . Já em 1885, na suécia, $O$ novo processo de polpação foi utilizado comercialmente, onde "as propriedades de resistência superiores foram reconhecidas e os novos tipos de papéis foram chamados papéis kraft ou fortes." SAMISTRARO (et al. 2009,p.1) afirma que a polpa proveniente do "kraft (palavra alemã 
que significa forte)", produz papéis possuindo uma resistência maior e de coloração escura. Hoje em dia o kraft é muito utilizado em embalagens, no artesanato, nos rolos de papel higiênico e etc. E assim como o papel branco é possível reciclá-lo a partir do mesmo processo sem dificuldades ou diferenças.

Assim, como vimos anteriormente o papel pode ser reciclado várias vezes e para evitar seu descarte na natureza a melhor solução é a sua reciclagem como alternativa positiva a extensão do seu ciclo de vida, assim a fig. 1 demostra o Ciclo de vida do papel kraft reciclado que nunca é finalizado se sempre for reciclado.

Figura 1- Ciclo de vida do papel kraft reciclado

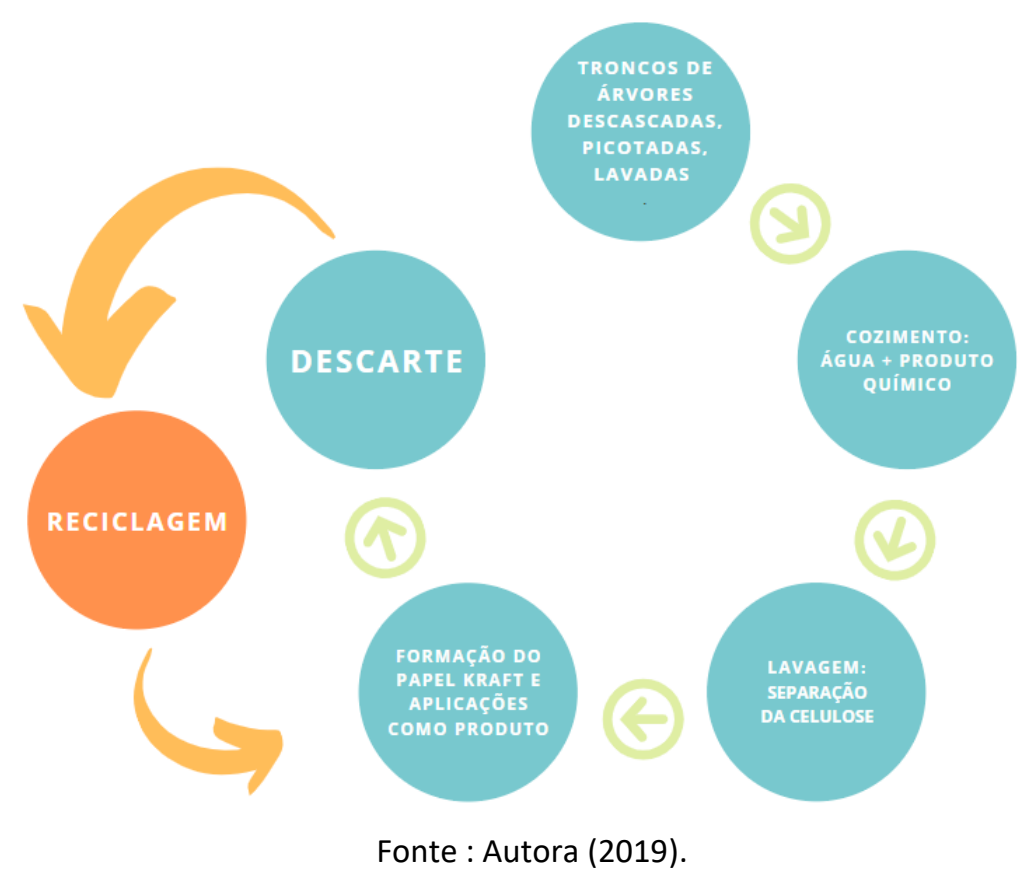

O papel kraft, em sua produção normal, começa com a coleta de troncos de árvore que são cortadas, lavadas, cozidas, lavadas pela segunda vez para a separação da celulose e por último a formação do papel kraft. Assim como o papel branco, durante sua produção, recebe adição de produtos químicos em seu cozimento, porém ainda sim ele é mais sustentável que o branco que recebe mais outros produtos químicos para o seu branqueamento. O processo de reciclagem do papel kraft não é necessário adição de produtos químicos problemáticos ao meio ambiente.

Também, no que diz a respeito a aplicação do papel kraft reciclado ou "normal", estes podem ser usados para tags, sacolas, convites, lembrancinhas, cadernos, etc. Sua cor amarronzada e natural permite um aspecto rústico onde é aplicado, mas também é possível a aplicação de cores.

\section{Materiais e métodos}

O papel utilizado neste trabalho foi coletado de rolinhos descartados de papel higiênico, e aparas resultantes do processo de encadernação da empresa OrliTha D\&A. E para reciclar é necessário ter em mãos alguns materiais para a realização, os quais citam o liquidificador, recipientes apropriados, cola, telas com tramas abertas, tela vazada, TNT, prensa, varal e pregador. A figura 2 ilustra as etapas necessárias para a reciclagem do papel. 
Figura 2 - Metodologia para reciclagem de papel

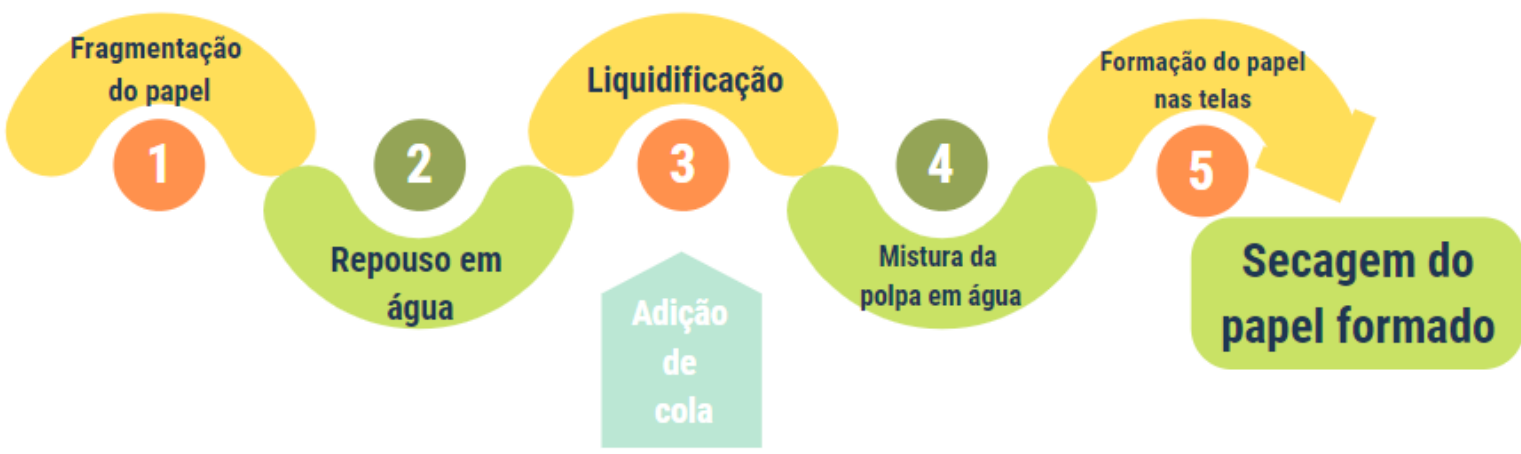

Fonte : Autora (2019).

Para o desenvolvimento do papel reciclado de kraft, é necessário coletá-los para realizar o processo de experimentação, assim os mesmos podem vir principalmente de resíduos industriais. Logo após coletado, o mesmo é despinicado manualmente ou triturado com ajuda de algum maquinário, como liquidificador, como ilustra a figura 3.

Figura 3 - Papel coletado e triturado no liquidficador

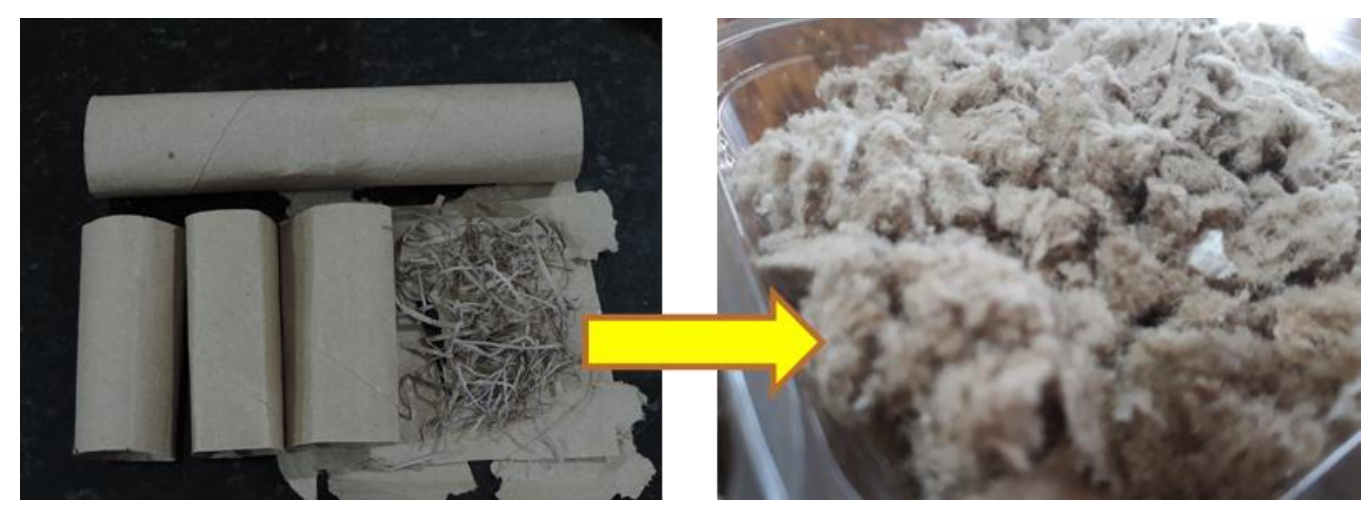

Fonte : Autora (2019).

Para esse experimento, foi triturado um total de $0,215 \mathrm{~g}$ de fibra de kraft. Onde depois o papel fragmentado foi colocado em repouso no recipiente, figura 4, por mais de um dia para amolecer as fibras e para facilitar a etapa posterior.

Figura 4 - fibra em repouso

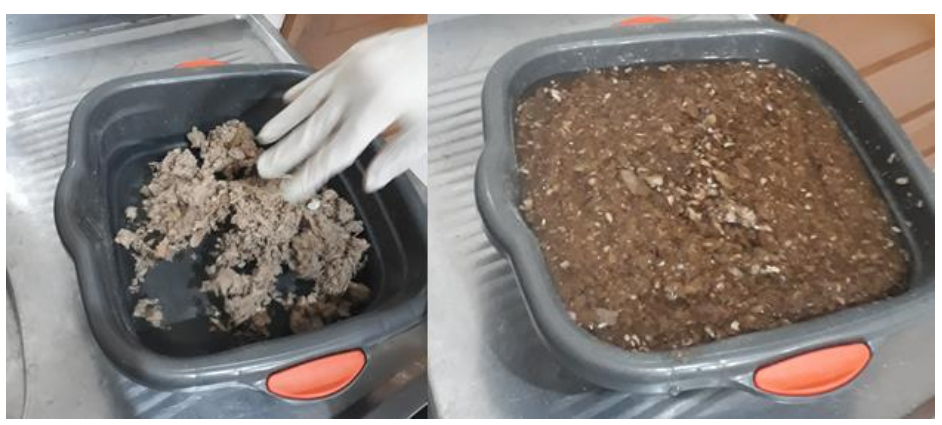

Fonte : Autora (2019).

A liquidificação e adição de cola é a próxima etapa, a qual é demonstrada na figura 5. 
Figura 5 - Liquidificação

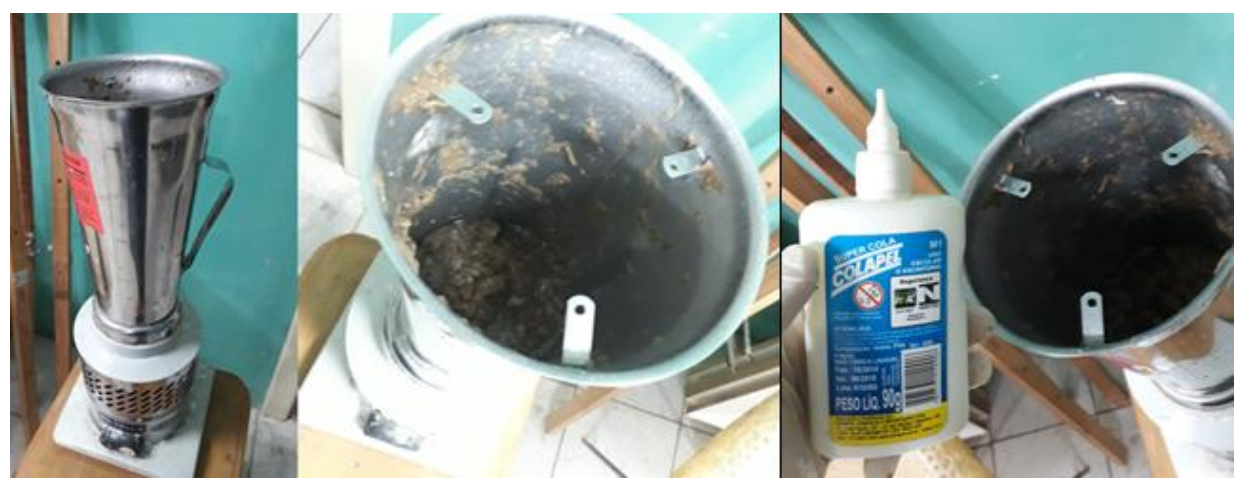

Fonte : Autora (2019).

Nesse experimento foi batido apenas 5 xícaras de polpa com 2,5 litros de água e foi adicionado menos de uma colher de chá de cola escolar para melhor junção das fibras. Além disso, a polpa foi misturada em uma bacia de água contendo 14 litros de água, figura 6.

Figura 6 - Polpa misturada na bacia com água

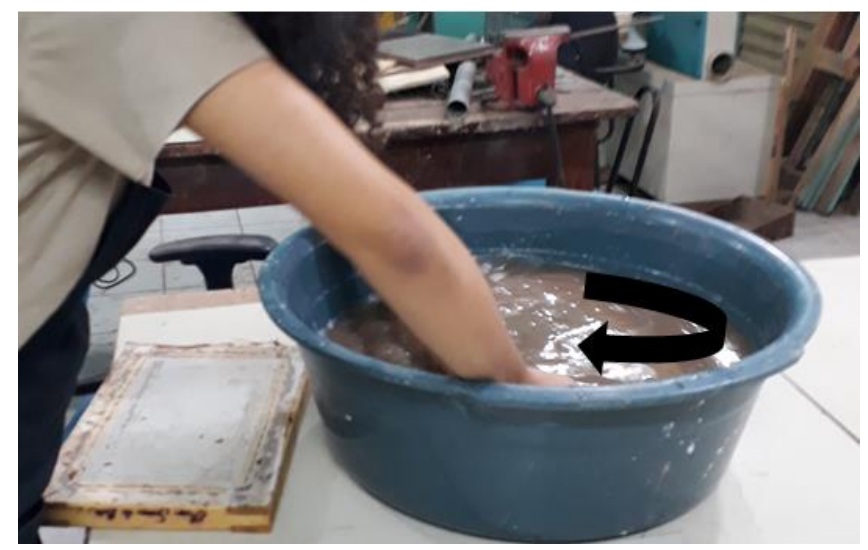

Fonte : Autora (2019).

O papel é formado nas telas de tramas abertas como mostra a figura 7.

Figura 7 - Tela de trama aberta

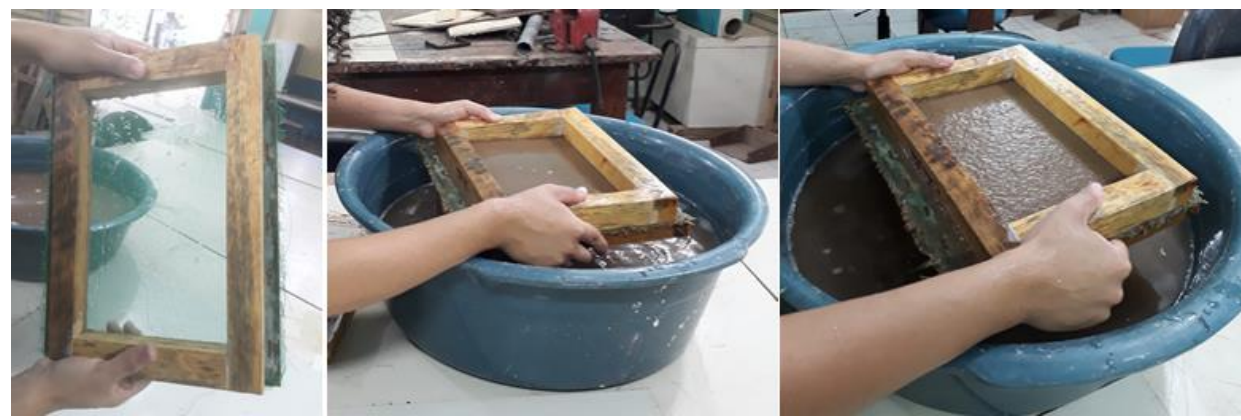

Fonte : Autora (2019).

Essas telas são mergulhadas e puxadas da bacia com a polpa, a imagem 8 demostra com clareza a realização desse processo. 
Figura 8 - Tela mergulhada para formação do papel

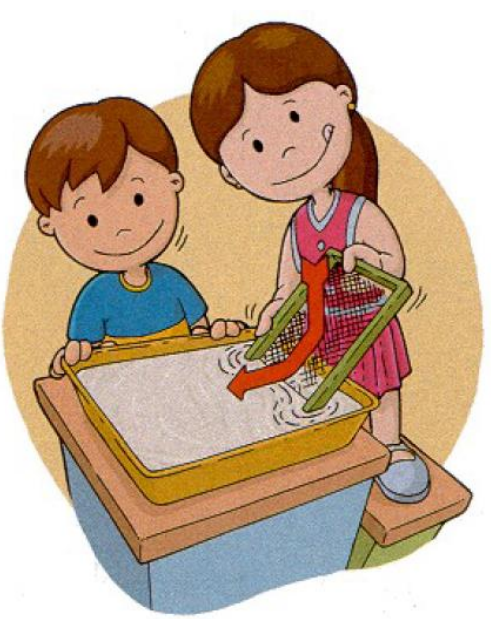

Fonte : FUNDACENTRO (2002).

Para uma espessura maior de papel é necessário a utilização de uma tela vazada, como mostra a figura 9.

Figura 9 - As telas necessarias para formação do papel com espessura maior

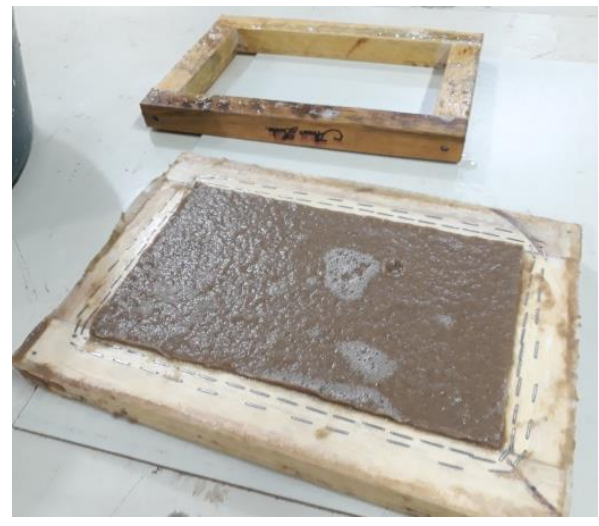

Fonte : Autora (2019).

O papel formado é passado para o TNT, figura 10.

Figura 10 - Papel transferido para o TNT

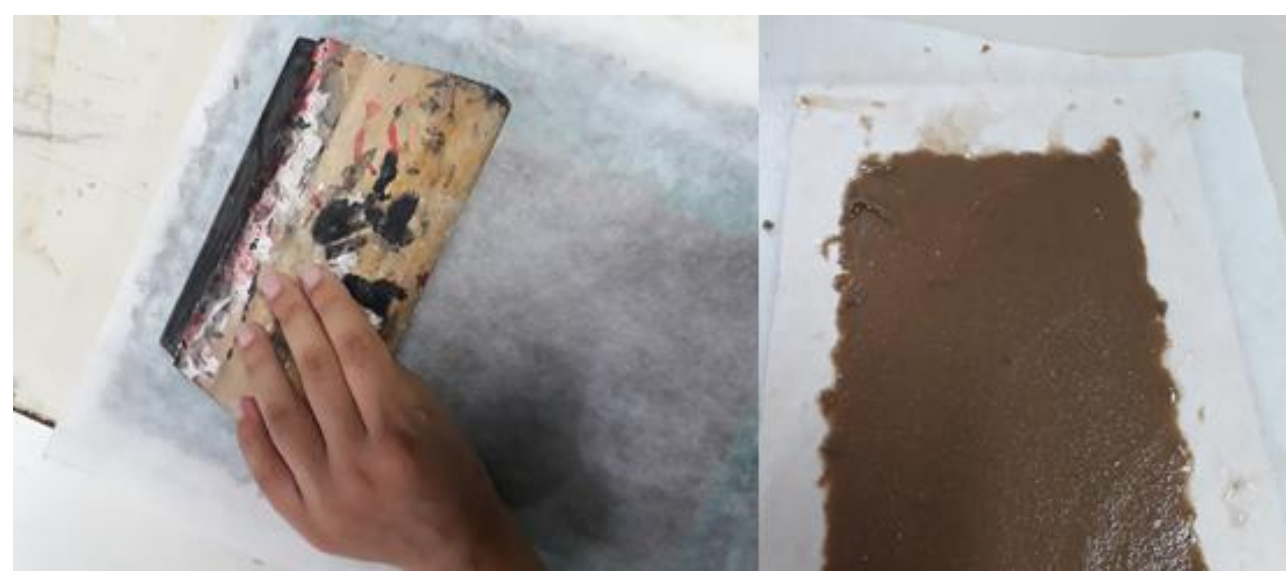

Fonte : Autora (2019). 
No TNT, o papel é prensado para a retirada do excesso de água e para a rápida secagem, figura 11.

Figura 11 - Prensa improvisada para a secagem do papel

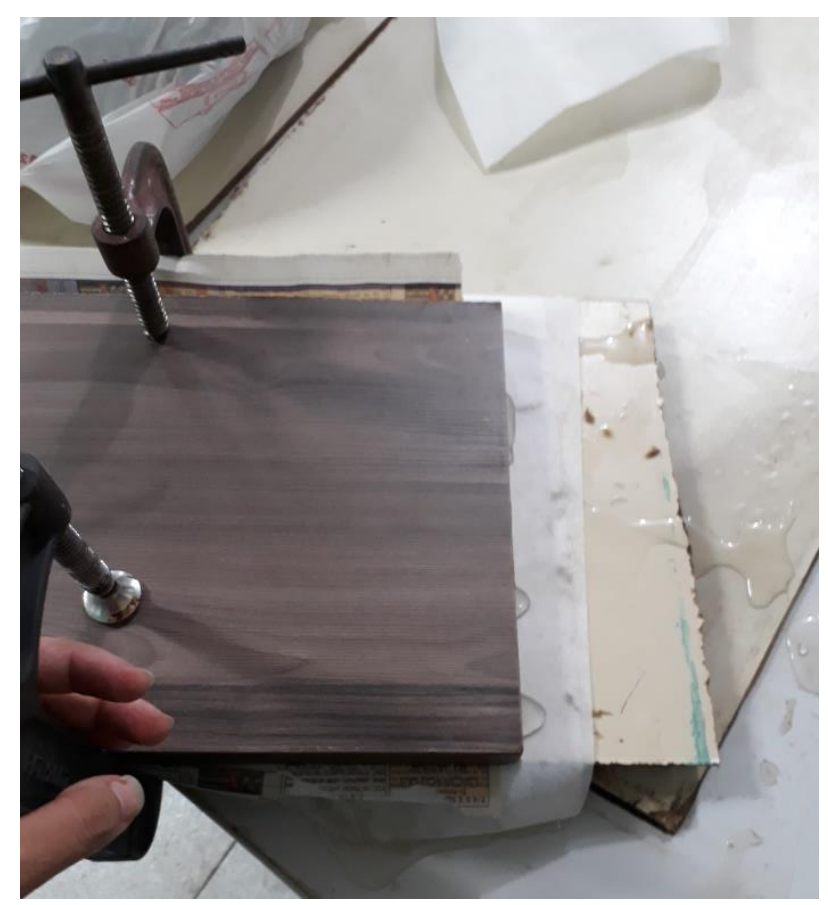

Fonte : Autora (2019).

A secagem é a última etapa para a finalização do papel que foi reciclado, onde o mesmo é colocado suspenso em um varal.

Figura 12 - Retirada do papel do TNT

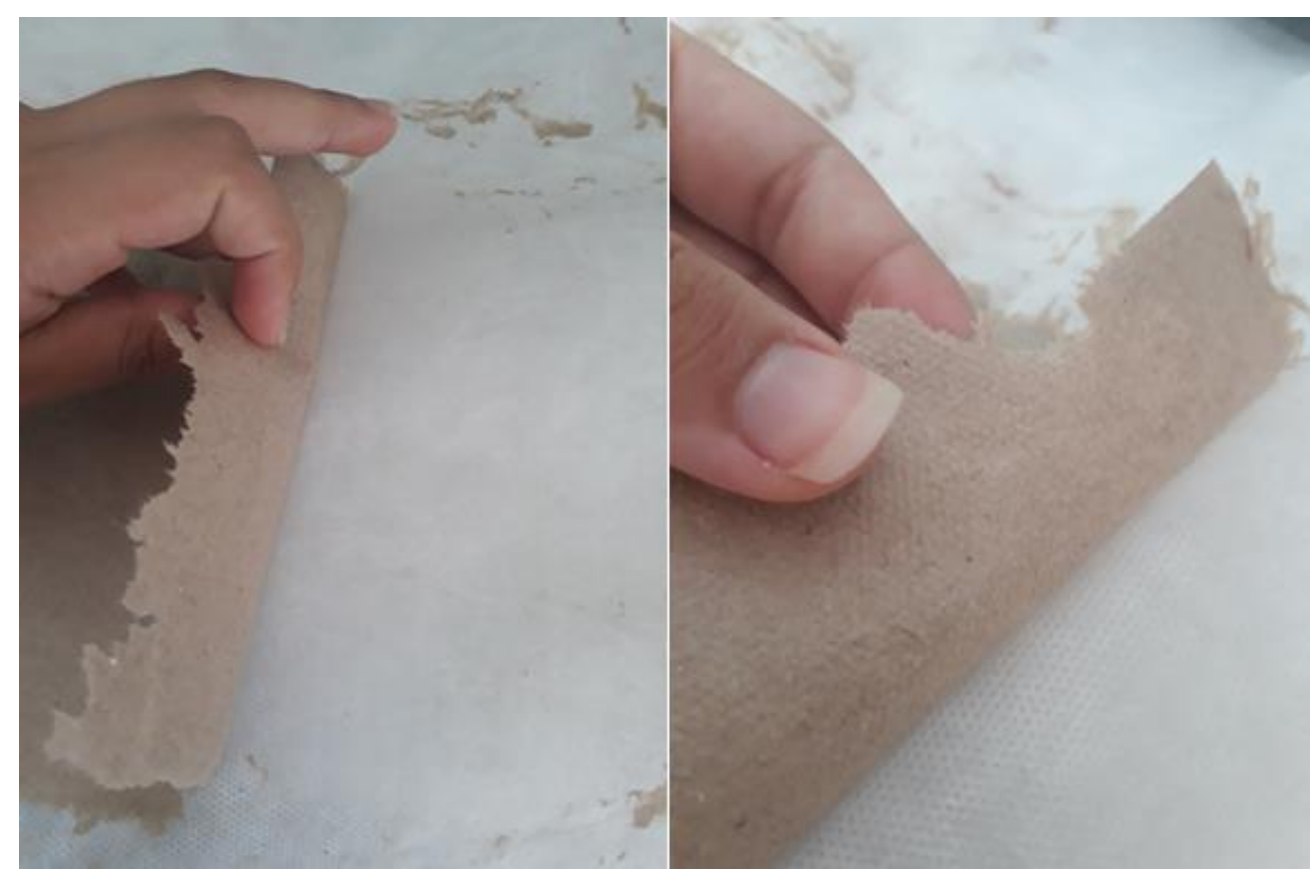

Fonte : Autora (2019).

Dependendo da temperatura ambiente o processo de secagem pode demorar 24 horas. 
Quando já seco, o papel pode ser removido facilmente do TNT, Imagem 12.

Também usando o mesmo processo, procurou-se ainda para amenizar a os impactos e custos na produção do papel, realiza-lo sem a adição de cola. E o papel obtido foi usado para encapar um caderno produzido artesanalmente.

\section{Resultados}

O papel que foi gerado artesanalmente possui diferenciação de um para outro, onde nas 6 amostras coletadas de papel com adição de cola e 6 sem cola, percebeu-se em alguns casos a aderência das fibras uma a outra de maneira não uniforme, onde ao observar as amostras contra a luz, em alguns casos a passagem de luz no papel foi mais presente que em outras, como mostra a imagem 13.

Figura 13 : Papel contra luz.

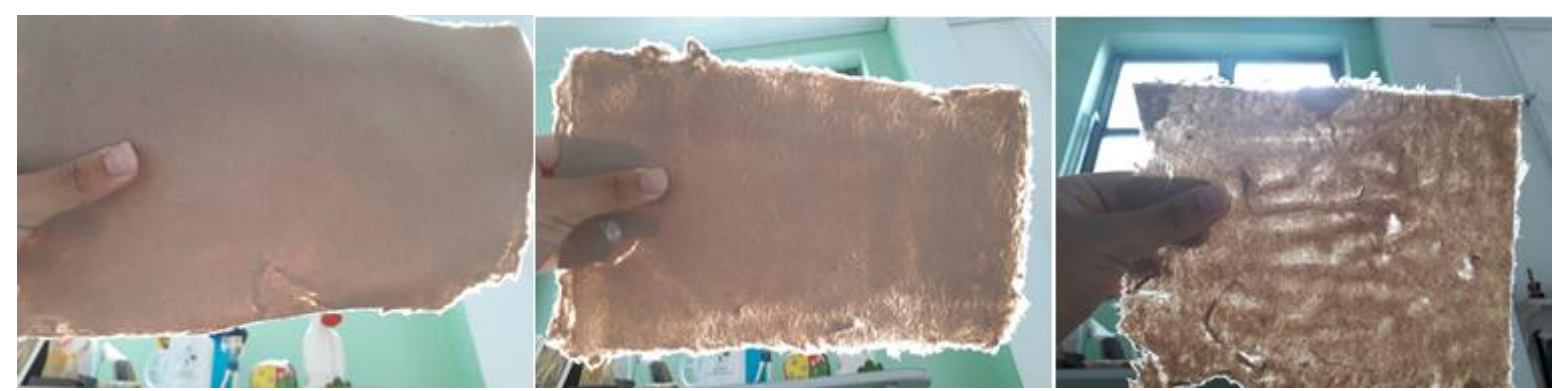

Fonte : Autora (2019).

Os papeis reciclados de kraft permitem a aderência da tinta de caneta como os outros papeis. Já em relação a outros testes como impressão é necessário um estudo mais aprofundado em relação a reciclagem. Não foi utilizado produtos para clareamento do material e caso não use cola, macroscopicamente as diferenças não são perceptíveis, figura 14.

Figura 14 - Comparações macroscópica dos papeis

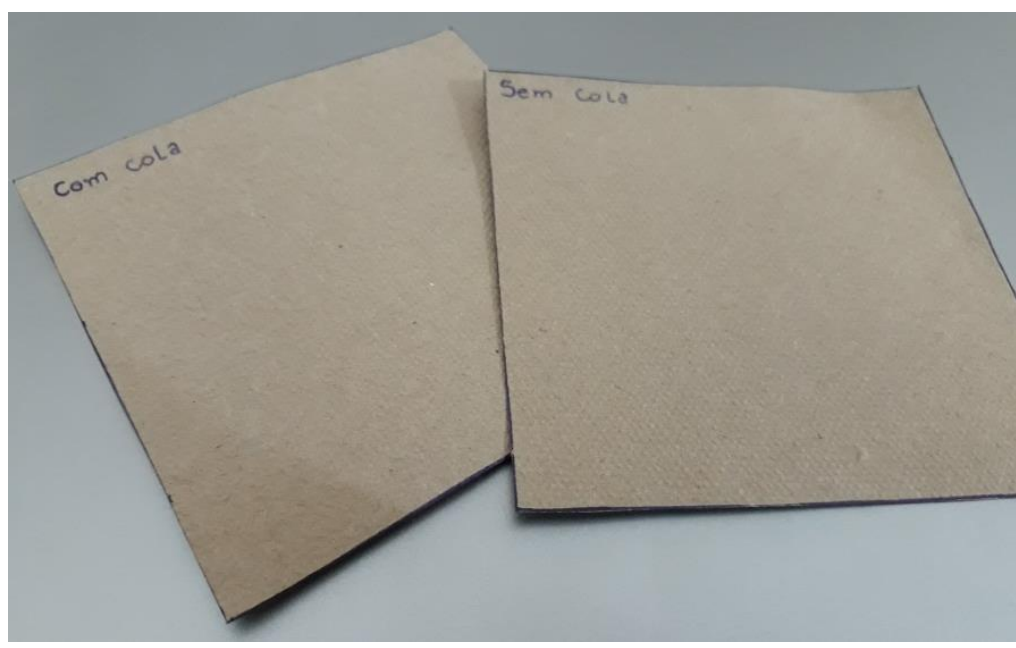

Fonte : Autora (2019).

Todavia de acordo com Josep Asunción (2002,p.28), a cola permite impermeabilidade ao papel e sem ela o papel é mais absorvente. Outrossim, foi observado que o papel com cola perde menos umidade que o que não apresenta a mesma, mas ainda sim é necessário um estudo mais 
aprofundado dos assuntos em questão. Além disso, também não foi utilizado todas as $0,215 \mathrm{~g}$ de papel triturado, e não se calculou a capacidade total de quantos papeis seriam produzidos com tal quantidade.

O papel apresenta maleabilidade e possibilitou encapar um bloco de anotações facilmente, como pode-se observar na imagem 15, onde mostra um bloco de anotações totalmente artesanal feito pela empresa OrliTha com as amostras coletadas de papel reciclado de kraft .

Figura 15 - Produto feito usando papel Kraft
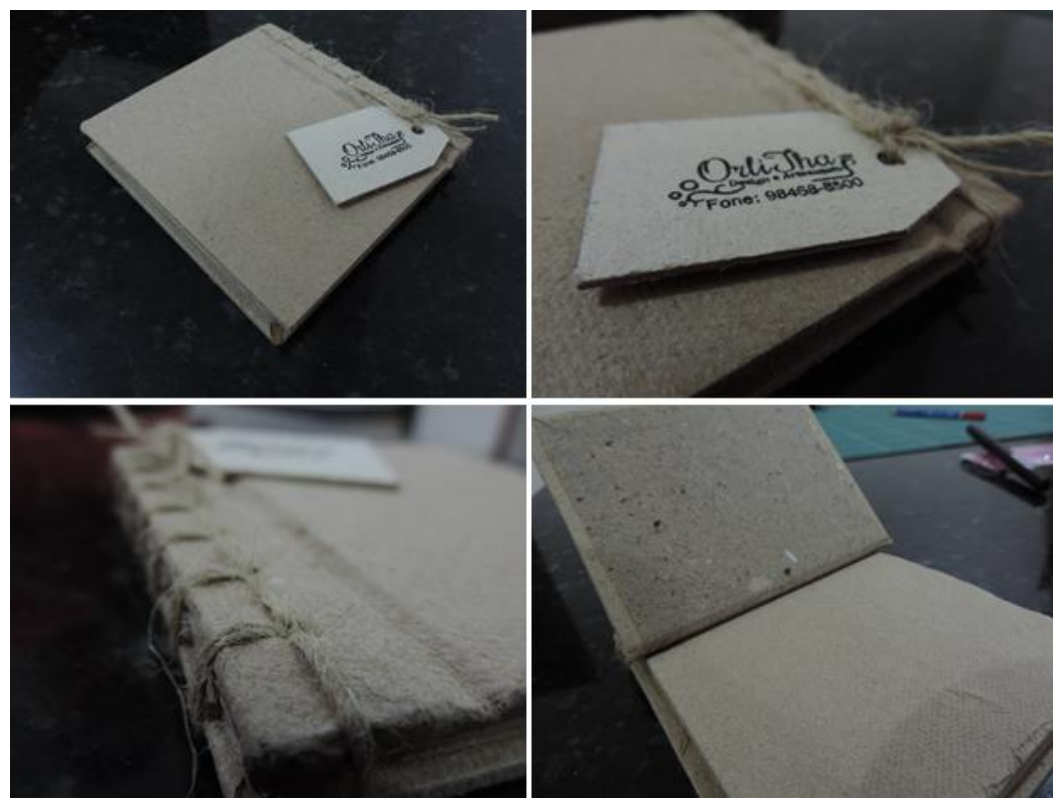

Fonte : Autora (2019).

O bloco de anotações é feito com capa dura de papel paraná, encadernação japonesa com linha de juta. Apresenta tamanho aproximado de $10,3 \mathrm{~cm}$ de altura e $11 \mathrm{~cm}$ de largura. A cor é do próprio papel kraft, marrom claro.

\section{Considerações finais}

Atualmente tem-se consciência que existe formas de evitar o descarte inadequado na natureza dos produtos inutilizados e uma delas é a reciclagem. Em uma empresa, o papel está como um resíduo aparente (documentos, informativos, etc.). Os papeis descartados, inclusive o de kraft, pode ser reciclado várias vezes, impedindo a finalização do seu ciclo de vida e seu descarte inadequado no meio ambiente.

Muito utilizado para escrita e aplicado na fabricação de cadernos, bloco de anotações, recibos e etc., o papel que for reciclado ainda pode ser usado para a realização do mesmo. 0 resultado de um produto construído com materiais descartados é a proteção do meio ambiente, o aumento de vida útil das reservas naturais e a diminuição do impacto ao capital natural, além da redução de locais para aterro por causa do pouco volume de resíduos descartados.

Portanto, reciclar, não só papeis, mas também outros produtos é uma forma de garantir a qualidade de vida das gerações atuais e futuras. 


\section{Referências}

AFONSO, C. Sustentabilidade: caminho ou utopia?. São Paulo: Annablume, 2006.

ASUNCIÓN, J. O Papel: técnicas e métodos tradicionais de fabrico. Lisboa : Estampa, 2002.

KAZAZIAN, T. Haverá idade das coisas leves: design e desenvolvimento sustentável. São Paulo: Senac, 2009.

MANZINI, E. Design para inovação social e sustentabilidade comunidades criativas, organizações colaborativas e novas redes projetuais. Rio de janeiro: e-papers, 2008

MANZINI, E.; VEZOLLI, C. O Desenvolvimento de Produtos Sustentáveis. São Paulo : Editora da Universidade de São Paulo, 2016.

MORAIS, M. et al. Um estudo sobre a reciclagem de papel: Um panorama desta atividade no Brasil. Revista Científica Semana Acadêmica. Fortaleza, 2015, p.1 - 9.

ROSA, B. et al. A importância da reciclagem do papel na melhoria da qualidade do meio ambiente. XXV Encontro Nac. de Eng. de Produção - Porto Alegre, 2005, p. 1-7.

SAMISTRARO, G. et al . Previsão das propriedades físicas do papel kraft por espectroscopia no infravermelho próximo (NIR) e regressão por mínimos quadrados parciais (PLS). Quím. Nova, São Paul, 2009, p. 1422-1425.

SOUZA, L.; SILVA, E. ; JUNIOR, R. Resíduos da construção civil: reaproveitamento do kraft e utilização do marketing verde. VII Congresso norte nordeste de pesquisa e inovação. Palmas Tocantins, 2012, p. $3-6$.

VIEGAS, J.; SALLES, M. A sustentabilidade em projetos de produto: uma abordagem ambiental. VIII Congresso nacional de excelência em gestão 2012, p. 1 - 15. 